\title{
TESTES ESPECIAIS NO DIAGNÓSTICO DA DISFUNÇÃO ERÉTIL
}

\author{
Alfredo Romero \\ Paulo Canella ${ }^{2}$
}

Até o início dos anos 80, causas psicogênicas eram consideradas a etiologia em até 90\% das disfunções eréteis. Atualmente, crê-se que é significativa a gênese orgânica, como fator desencadeante destas disfunções.

$\mathrm{Na}$ tentativa de diferenciar as disfunções sexuais psicológicas, orgânicas ou mistas, apareceu, entre o meio da década de 70 e até a metade da década de 80 e, mais recentemente, uma série de testes diagnósticos, cuja finalidade é um melhor esclarecimento das disfunções sexuais ligadas às três fases da resposta sexual masculina: Desejo, Excitação e Orgasmo. Vejamos os principais métodos diagnósticos para as disfunções eréteis.

\section{1-TESTES DIAGNÓSTICOS com Fármacos Vasoativos (Teste de ereção fármaco-induzido, teste farmacológico e teste de ereção).}

Este método surge na década de 80, com a injeção intracavernosa de substâncias vasoativas, vindo a ocupar um papel básico no protocolo diagnóstico do homem com disfunção erétil, permitindo em muitos casos que a avaliação clínica chegue a um diagnóstico mais seguro.

\footnotetext{
${ }^{\prime}$ Cirurgião vascular; mestrando em Sexologia-UGF/RJ

E-mail: saudesexual@ibrasexo.com.br

${ }_{2}^{2}$ Professor Titular do Mestrado em Sexologia da UGF/RJ e do Instituto de Ginecologia da UFRJ-E-mail:paraobastos@ig.com.br
} 
0 método foi descrito por Virag, em 1982, ao injetar diretamente no sistema arterial peniano cloridrato de papaverina. Posteriormente, o autor injetou o fármaco no corpo cavernoso, observando que se produzia uma resposta erétil prolongada, quando não existia patologia erétil vascular e descreveu a técnica como método diagnóstico para a disfunção erétil.

Atualmente, o cloridrato de papaverina foi substituido pela Prostaglandina E1 (PGE1), a qual é melhor tolerada pelos pacientes. As drogas intracavernosas produzem: relaxamento da musculatura lisa do corpo cavernoso, favorecendo a ereção por uma dilatação arterial, aumentando o aporte sangüineo peniano e a constrição venosa, valorizando a fase final da ereção, o relaxamento da musculatura sinusoidal e o enchimento sangüíneo dos corpos cavernosos.

Assinale-se que pode haver respostas falso-positivas em pacientes com disfunção erétil de origem neurogênica, já que os efeitos sobre o músculo liso eliminam o mecanismo neural necessário para uma resposta erétil normal.

Indicações - Quando na avaliação clínica não encontrarmos dados que nos aproximem de uma suspeita fundamentada do diagnóstico etiológico da disfunção erétil, o passo seguinte é a realização de testes com fármacos vasoativos, que podem ser úteis nas seguintes situações:

- Estudo da patologia vascular.

- Constatação de ereção normal em pacientes disfuncionais de causa presumivelmente psicológica.

- Como complemento técnico de outras explorações no protocolo da disfunção erétil: cavernosometria e cavernosografia. Doppler e angiografia peniana.

- Para o controle evolutivo de determinadas operações penianas: como curvaturas, doença de Peyronie, cirurgia arterial e por escape venoso. 
e naqueles homens que queixam-se do tamanho do pênis em ereção ou flacidez, em comprimento ou em grossura.

Técnicas - As técnicas mais utilizadas são as seguintes:

- Papaverina: 3 aplicações de 25, 50 e 100mg, dependendo da resposta positiva (+) ou negativa (-) a cada dose.

- $30 \mathrm{mg}$ de cloridrato de papaverina com 0,8mg de fentolamina.

- Prostaglandina E1, ampola de 500 microgramas diluída em $19 \mathrm{ml}$ de soro fisiológico, tendo uma diluição de 25 microgramas $/ \mathrm{ml}$. Usamos seringa de insulina e como dose padrão injetamos $20 \mathrm{UN}$ que correspondem a 5 microgramas de prostaglandina $\mathrm{E}_{1}$ por dose.

\section{Resultados}

A resposta normal. Aos 5-10 minutos, surge ereção firme à palpação com um ângulo de $90^{\circ}$ ou mais e uma duração variável, em geral superior a uma hora. Podemos observar:

- Ausência de rigidez. Podendo haver certo grau variável de tumescência e mudanças no diâmetro peniano.

- São freqüentes os resultados falso-negativos. Um paciente ansioso, ou muito estressado, pode não alcançar ereção completa pelo medo da injeção ou pela pressão ambiental.

- Resposta caprichosa. Por vezes, há respostas não ajustadas à lógica, derivadas de indole psicológica e ambiental. Exemplos são as respostas tardias, nas quais só se obtém boa rigidez depois de o paciente ter abandonado o consultório. Também se observam respostas negativas em pacientes sem disfunção erétil (em estudos por curvatura peniana) e respostas mais deficientes que aquelas às quais o homem refere, na sua prática sexual.

Complicações - 0 uso de fármacos vasoativos, tanto para diagnóstico como para o tratamento da disfunção erétil, deve ser realizado sobre estrito controle médico, para evitar fenômenos secundários indesejáveis, 
principalmente o priapismo. Se não há remissão da ereção, procedemos à aplicação intracavernosa de fármacos vasoconstritores. Exemplo: cloridrato de etilefrina (Efortil), uma ou duas ampolas, adrenalina $(0,5 \mathrm{ml}$ a 1:1000), noradrenalina, metaraminol, dopamina, etc.

\section{2- Tumescência peniana noturna (Npt)}

A rigidez peniana, que é a relação entre a pressão intracavernosa e o volume do corpo cavernoso, é o melhor parâmetro para se avaliar a capacidade de penetração do paciente. Como todos os homens desenvolvem episódios noturnos de ereção, 4 a 6 por noite, com características conhecidas (KaracanTullii), podem ser estudadas estas ereções para diferenciar as disfunções eréteis psicogênicas das orgânicas. Durante algum tempo, foi o método de escolha para diferenciar estas duas etiologias, porém, metodologias mais recentes vieram a substituir tal método.

As ereções fisiológicas que o homem tem de forma regular, durante as fases paradoxais do sono (caracterizadas pela presença de movimentos rápidos dos olhos- REM) é um fenômeno natural, sem estimulo sexual consciente, cujo mecanismo de ação é similar ao que acontece na ereção estimulada sexualmente. Esta ereção está presente também na fase não REM do sono. A duração total aproximada, destes episódios eréteis, é de 90 minutos, o que eqüivale a $20 \%$ do tempo total de sono. A sua duração, qualidade e freqüência dos diferentes episódios eréteis variam com a idade. Entre os 20 e 29 anos, o tempo médio de um episódio de tumescência peniana noturna é de 38 minutos; entre os 61 e 67 anos, é de 27 minutos.

Indicações - Verificação da capacidade orgânica de ereção dos indivíduos com queixa de disfunção erétil.

Técnicas - Há vários métodos. Karacan introduziu o método denominado 
na base e na ponta do pênis, durante o sono, para determinar variações do diâmetro peniano. Diâmetros menores de $16 \mathrm{~mm}$ caracterizavam ereções parciais; superiores a esta medida, permitiam uma penetração vaginal.

Em 1980, Barry propôs método simples baseado na utilização de selos, colocados ao redor do pênis, formando um anel (stamp-test). Se o paciente ao acordar observava os anéis rompidos pela linha de pontos, isto era indicativo da presença de ereção.

Em 1983, a Dacomet Corporation introduz outro método simples, denominado snap-gauge, consistente em um anel formado por 3 bandas de plástico de cores diferentes, unindo ambos os extremos, colocado ao redor do pênis e fixo por velcro. Cada banda rompia-se a partir de determinada força em 285 a 567g, respectivamente. 0 teste era indicativo da ausência de ereções, quando não havia rompimento de nenhuma banda, ou de diferentes graus de ereção, quando algumas delas estavam separadas. Estas técnicas tinham, como inconveniência, medir unicamente as tumescências e as variações do diâmetro peniano, sem valorizar a rigidez, o número e a duração dos diferentes episódios de ereção.

Wein e cols., em 1981, demonstraram que 42\% dos pacientes considerados normais, com estas técnicas, não apresentavam rigidez suficiente para poder realizar um correta penetração vaginal.

Em 1985, Bradley e Timm introduziram o Rigiscan, que permite medir a variação do diâmetro do pênis e a rigidez deste. 0 método consiste em dois anéis colocados na base e na ponta do pênis, adaptáveis ao tamanho de cada órgão. Este aparelho registra as mudanças de tamanho expressadas em centímetros e as de rigidez em porcentagem. Compõemse de duas unidades: uma de gravação ambulatorial, que armazena os registros de tumescência e rigidez, e um computador com impressora, que processa e imprime os dados obtidos. A unidade de gravação ajusta-se à coxa do paciente através de uma cinta e os anéis medidores ajustam-se na base e ponta do pênis. Estes últimos têm um intervalo 
de distensão entre 5 e $15 \mathrm{~cm}$ de diâmetro. Ao ligar o aparelho, os anéis se contraem a cada 15 segundos, para medir o diâmetro peniano, afrouxando-se a seguir para não impedir a distensão erétil. Quando o diâmetro peniano varia em $1 \mathrm{~cm}$, inicia-se a medição da rigidez a cada 30 segundos, Quando varia menos de $1 \mathrm{~cm}$, o registro realiza-se a intervalos de 3 minutos.

Para a medição da rigidez peniana, os anéis se estreitam com uma força constante de 283,5g, determinando uma compressão radial do pênis, para obtenção do grau de rigidez.

Resultados - Segundo estudos realizados em populações de indivíduos normais, aceitam-se como valores de referência os seguintes:

- Freqüência dos episódios: 3-6 por noite, período de 8 horas.

- Duração de 1 episódio: 10-15 minutos.

- Tumescência na base: $3 \mathrm{~cm}$ de incremento em respeito à tumescência basal.

- Tumescência na ponta: $2 \mathrm{~cm}$ de incremento em respeito à tumescência basal.

- Rigidez ausente (inferior a 40\%), insuficiente (40-70\%), ótima (superior a 70\%).

Podem ser encontrados diferentes padrões de anormalidades que, mesmo não sendo considerados patognomônicos de determinadas patologias, podem ser sugestivos de anormalidade, alterações arteriais, alterações venosas, etc. Exemplos:

- Dissociação: indica uma falta de rigidez na porção distal do pênis. A tumescência e a rigidez da base são normais. Não obstante, existe uma alteração da rigidez da ponta, sendo normal ou não o registro da tumescência.

- Uncoupling: o registro da tumescência é normal, a rigidez encontra-se ausente ou é de qualidade insuficiente tanto na ponta como na base peniana. 
- Rigidez de curta duração: os episódios de rigidez são inferiores a 10 minutos de duração.

- Rigidez de pouca amplitude: apesar de o registro de tumescência ser normal, a rigidez da ponta e da base é inferior a $40 \%$.

- Ausência de tumescência e rigidez: a representação gráfica do traçado é plana.

Complicações - Não são assinaladas

\section{3- Estudo peniano com DOPPLER}

A primeira aplicação médica do principio que postulara, em 1843, Christian Andréas Doppler, foi realizada em 1956, pelo cardiologista japonês Sotomura, estudando o fluxo arterial periférico.

A análise não-invasiva do fluxo sangüineo, por procedimentos ultrassônicos, está baseada no princípio físico do efeito Doppler. Segundo este, quando uma onda de qualquer natureza incide sobre uma superficie em movimento, a onda refletida varia sua freqüência de forma proporcional à velocidade da superfície refletora. Aplicando este princípio, é possivel determinar a velocidade de um objeto, conhecendo a diferença entre as freqüências da onda incidente e a refletida. Esta freqüência diferencial é denominada freqüência Doppler. É positiva quando o objeto se aproxima do transdutor e negativa, em caso contrário. Os equipamentos ultrassônicos Doppler detectam e caracterizam o fluxo sangüineo, onde a fonte dos sinais eco são os elementos do sangue que circulam pelo interior dos vasos.

Segundo a emissão do feixe ultrassônico da fonte, ela pode ser continua (Doppler continuo) ou pulsátil (Doppler pulsátil). Pode ser obtido um registro gráfico do fluxo sistólico-diastólico.

Técnica: 0 estudo Doppler continuo é de fácil aplicação técnica e aparelhagem relativamente simples. Permite localizar as artérias dorsais 
do pênis na sua raiz e segui-las até sua porção terminal, ao nivel da região lateral bálano-prepucial.

Utiliza-se sonda de 8 a $10 \mathrm{MHz}$, explorando-se a face dorsal do pênis próximo à raiz, a cada lado da linha média, com o pênis em posição longitudinal em relação às coxas e suave tração. Aplica-se a sonda formando um ângulo quase de 90 graus com relação ao eixo longitudinal do pênis.

As artérias cavernosas, que são de localização mais difícil, exploram-se nas faces laterais do pênis a maior profundidade, utilizando-se uma sonda de 4 a $8 \mathrm{MHz}$ próximo a raiz do pênis, na região latero-ventral, apoiando o pênis sobre a parede abdominal em discreta tração, aplicase a sonda formando um ângulo reduzido de mais ou menos $10^{\circ} \mathrm{com}$ o eixo longitudinal do pênis.

0 Doppler continuo facilita a localização das artérias penianas dorsais e profundas, permitindo a medida da pressão sistólica das mesmas. Para isto, dispõe-se de um pequeno manguito de pressão, de $2-3 \mathrm{~cm}$ de largura por $9-10 \mathrm{~cm}$ de comprimento. Insufla-se proximalmente ao ponto de localização da artéria e, ao desinsuflá-lo, permite ouvir um primeiro fluxo, que coincide com a pressão sistólica.

Em múltiplos estudos, correlaciona-se essa pressão sistólica com a pressão sistólica braquial, resultando o índice pênis-braço.

Resultados - Em linhas gerais, pode-se afirmar que índices menores de 0,70 são indicativos de patologia vascular; entre 0,70 e 0,90 , são suspeitos, e indices acima de 0,90 são compativeis com a normalidade.

Os resultados falso-positivos produzem-se por confundir as artérias cavernosas com as dorsais. Estas últimas participam parcialmente no mecanismo da ereção e uma avaliação hemodinâmica neste nivel não coincide, em muitos casos, com as condições das artérias profundas ou 
Esta confusão costuma ser freqüente pela existência de uma colateral da artéria dorsal ao nivel da raiz do pênis. Os resultados falsos negativos podem ter a sua origem em causas técnicas (má colocação da sonda, opressão excessiva) ou serem atribuidos ao paciente por apresentar vasoespasticidade, ansiedade, ou estresse, que conduzem a situações simpaticotônicas que impedem a boa localização das artérias cavernosas. Em casos isolados, a exploração não pode realizar-se por um pênis excessivamente pequeno em estado de flacidez. Para evitar, em parte, estes problemas, estão utilizando-se procedimentos com aplicação intracavernosa de fármacos vasoativos, teste de hiperemia reativa e teste do roubo pélvico.

A combinação da técnica ultrassônica de imagens com Doppler contínuo ou pulsátil constitui o método exploratório conhecido como o método Dupplex. Associado com a injeção intracavernosa de substâncias vasoativas, permite-nos avaliar seletivamente a reatividade destas artérias e medir seu fluxo sangüineo. Em cortes transversais do pênis, apresentam-se as artérias cavernosas como duas linhas hiperecogênicas paralelas, que se parecem à representação gráfica matemática do símbolo de igualdade. Em cortes longitudinais, apresentam-se como duas linhas paralelas que percorrem da base a ponta dos corpos cavernosos (imagens de linha de trem).

Complicações - Não são assinaladas, é exame de mínimo risco.

\section{4-Cavernosometria e cavernosografia}

A disfunção erétil de origem venosa foi, durante muito tempo, desconhecida. Os conhecimentos sobre anatomia e fisiologia da resposta erétil fizeram intuir e depois comprovar a importância de uma diminuição ou supressão da drenagem venosa para a obtenção de um adequado grau de rigidez peniana. 
Conti, em 1952, baseando-se em observações histológicas, relaciona mecanismos hemodinâmicos da ereção com a existência de um shunt arteriovenoso, que atuando como uma autêntica comporta de drenagem venosa, deriva seu fluxo através dos corpos cavernosos, provocando a sua repleção ou evitando-os através das comunicações arteriovenosas, o que provocaria o estado de flacidez. Esta teoria, não compartida pelas atuais opiniões, marcou uma referência à importância do mecanismo venoso.

Michal, em 1973, define disfunção erétil de origem vascular como a incapacidade que tem o organismo de provocar ou proporcionar um fluxo sangüineo suficiente aos corpos cavernosos, associada com a impossibilidade de bloquear o retorno venoso em nível do mesmo corpo cavernoso.

Fitzpatrick, em 1975, consegue a visualização radiológica dos corpos cavernosos empregando contrastes iodados pela injeção intracavernosa, o que permite um melhor conhecimento da anatomia venosa.

\section{Cavernosometria}

A cavernosometria fundamenta-se na medida da pressão intracavernosa durante a ereção artificial, provocada de forma passiva, ao injetar soro fisiológico a fluxo variável, até conseguir uma pressão de 90-110 mmHg, que se considera normal com fluxos que oscilam entre $90-180 \mathrm{ml} / \mathrm{min}$.

Um fluxo suficiente em ausência de patologia venosa provoca uma repleção completa dos corpos cavernosos e a sua rigidez, que se traduz em uma ereção normal, o que se objetiva na medição da pressão intracavernosa. Uma vez conseguida a ereção, a manutenção desse fluxo produz um aumento da pressão intracavernosa e o paciente refere dor, que pode ser intensa. A diminuição do fluxo a valores que se situam entre $40-50 \mathrm{ml} / \mathrm{min}$. mantém a ereção; este parâmetro é conhecido como fluxo de manutenção e aumenta, quando existe patologia venosa. 
Técnica - A metodologia do exame é a seguinte:

-Para perfusão do soro fisiológico nos corpos cavernosos, utiliza-se uma bomba de fluxo variável, cujo aporte volumétrico oscila entre $20 \mathrm{ml} /$ minuto a $400 \mathrm{ml} /$ minuto.

-A medição da pressão se faz no monitor, que expressa valores de pressão em mmHg.

Usam-se equipos de soro convencionais, em cujo extremo se conecta uma agulha de $0,9 \mathrm{~mm}$ de diâmetro (scalp 19), com a qual se puncionam os corpos cavernos. Anestesia-se o local com Xilocaína, mepivacaina, etc. a $2 \%$, usando-se agulhas de $0,9 \mathrm{~mm}$ de diâmetro.

-Com o paciente em decúbito dorsal, prossegue-se da seguinte maneira: Assepsia com povedine iodado, colocação de campos estéreis, infiltração anestésica na face lateral do pênis; esta punção deve ser superficial, com o cuidado de não infiltrar o interior dos corpos cavernosos, o que poderia alterar a resposta peniana. Punção com agulha de $0,9 \mathrm{~mm}$ do corpo cavernoso de um lado, conectado ao sistema de perfusão salina, o qual está conectado à bomba de perfusão. Punção com agulha de $0,9 \mathrm{~mm}$ do corpo cavernoso contra lateral, conectada a um sistema de monitorização de pressão.

-Ajuste dos equipamentos

-Início da perfusão nos corpos cavernosos a fluxos progressivamente crescentes: 50, 75, 100, 125, 150, 175, 200, 225 e 250 ml/min., mantendose durante 20 a 30 segundos. De forma sistemática, valoramos o fluxo e a pressão quando se inicia a tumescência, ao início da ereção e quando esta alcança o seu máximo grau, momento em que o paciente pode referir dor de intensidade crescente, o que indica necessidade imediata de interromper o fluxo de perfusão progressivo, tomando nota da pressão intracavernosa que terá superado $110 \mathrm{mmHg}$.

Resultados: Quando se obtém fluxo superior a $200 \mathrm{ml} / \mathrm{min}$. sem alcançar 
uma ereção suficiente e sem conseguir aumentos significativos da pressão intracavernosa, o diagnóstico será de fuga venosa.

Os valores aceitos como normais referentes ao fluxo de manutenção da ereção situam-se em 40-50 ml/min.

Esta exploração nos permite, quando patológica, afirmar a existência de alteração venosa e avaliar a possibilidade de uma intervenção cirúrgica na rede venosa, como solução da falha erétil.

Complicações - prendem-se aos acidentes com o procedimento, e são raros.

\section{Cavernosografia}

A cavernosografia consiste no estudo radiológico dos corpos cavernosos e de sua drenagem venosa após injeção intracavernosa de soro e contraste, através de uma bomba de débito variável, o que permite tipificar os débitos necessários para induzir e manter uma ereção.

A cavernosografia tem, como objetivo, o estudo funcional do sistema de drenagem venoso e anatômico dos corpos cavernosos do pênis. É indicada para estudo da moléstia de Peyronie, avaliação do sistema valvular, traumatismos penianos, trombose dos corpos cavernosos, suspeita de fistula cavernoso-esponjosa ou cavernoso-uretral, fibrose de septo intracavernoso, priapismo, sendo que alguns autores preferem a denominação PIPE (ereção prolongada por indução farmacológica) (papaverina).

A cavernosografia também foi realizada por alguns autores para o estudo dos corpos cavernosos no implante de próteses penianas e para o estudo evolutivo dos carcinomas penianos e prostáticos.

A drenagem dos corpos cavernosos é complexa, sendo a principal via de drenagem representada pelas veias cavernosas. A veia dorsal superficial faz a drenagem do prepúcio, enquanto a veia dorsal profunda faz a da glande e dos corpos cavernosos, e as veias bulbouretrais, do corpo esponioso. 
Técnica - 0 procedimento é semelhante ao da cavernosometria, sendo injetados $5 \mathrm{ml}$ de contraste diluídos em $5 \mathrm{ml}$ de solução salina, infundidos lentamente numa velocidade aproximada de $1 \mathrm{ml} / \mathrm{s}$.

-É tomada, então, uma radiografia no minuto zero, com o pênis em flacidez e em ântero-posterior.

-Posteriormente, o pênis é induzido à ereção, com a bomba de ereção artificial, até conseguir-se uma pressão intracavernosa em torno de 100 $\mathrm{mmHg}$, quando se injetam mais $10 \mathrm{ml}$ da solução de contraste e obtémse cinco radiografias, no minuto zero e nos $1^{\circ}, 3^{\circ}, 5^{\circ}$ e $10^{\circ}$ minutos.

Resultados - Visualisam-se as condições anatômicas da rede venosa e eventual diminuição ou supressão da drenagem das veias para a obtenção de um adequado grau de rigidez peniana. 0 exame permite verificar defeitos nos mecanismos hemodinâmicos da ereção, checando o shunt arteriovenoso. A drenagem venosa, o fluxo venoso através dos corpos cavernosos e as comunicações arteriovenosas são estudadas radiologicamente. Visualizam-se eventuais defeitos orgânicos na capacidade de proporcionar um fluxo sangüineo suficiente aos corpos cavernosos, ou na impossibilidade de bloqueio do retorno venoso a estas estruturas, base do mecanismo de ereção.

Complicações - prendem-se aos acidentes com o procedimento e a reações alérgicas (previsiveis e que podem ser previnidas) aos contrastes. São raras.

\section{Arteriografia Pudenda}

As imagens angiográficas são indispensáveis para o estudo das doenças arteriais, assim como para indicações cirúrgicas, sendo também úteis no controle pós-operatório. As imagens que se obtém correspondem à realidade anátomo-funcional da árvore arterial do individuo doente, no momento em que se realiza o exame. 
Nos casos de prováveis lesões tronculares aorto-ilio-hipogástricas, freqüentes nos doentes com arteriopatia dos membros inferiores, ou com doença aneurismática e que têm queixas de disfunção erétil, deve-se começar por uma arteriografia global que permita uma análise sumária do conjunto da bifurcação aórtica, do setor ilíaco e das artérias da bacia. Este estudo pode ser feito por aortografia translombar (punção de forma ascendente no ângulo costo-vertebral esquerdo de forma a atingir a aorta ao nivel de D11-D12) ou pela técnica de Seldinger (cateterismo da aorta, a partir de punção única na artéria femoral comum).

$\mathrm{Na}$ ausência de lesões do setor aórtico-iliaco comum, pratica-se uma arteriografia seletiva das duas hipogástricas direita e esquerda.

0 grande avanço tecnológico em matéria de intensificadores de imagens, digitalização das mesmas, memorização e vídeo tem facilitado a realização deste exame e tem permitido avanços que melhoram a qualidade da informação com menos riscos para o doente.

Técnicas - Proposta por J.F. Ginestie, divulgada e modificada por Michal, a exploração arterial radiológica necessita de uma técnica precisa e um rigor absoluto na leitura das imagens radiográficas. Foram Ginestie e Romieu que tiveram o mérito de realizar as primeiras explorações angiográficas seletivas das pudendas e descrever a técnica, que ainda hoje se pratica, assim como o de sistematizar as lesões.

0 aparecimento e desenvolvimento constante das técnicas não-invasivas (Ultrassonografia Doppler, Eco-Doppler) permitiram que a angiografia seletiva da hipogástrica pudesse ser cada vez mais utilizada de forma selecionada, servindo ao estudo não-invasivo, como guia para a indicação da sua realização, nos casos de disfunção erétil de origem vascular com provável indicação cirúrgica.

Além da arteriografia abdominal, que deve ser usada quando há suspeita de uma estenose aórtica ou iliaca a arterioorafia seletiva da 
iliaca interna é a melhor técnica para a investigação da artéria pudenda interna e dos seus ramos.

A dificuldade de conseguir uma dilatação substancial e reprodutivel da rede peniana levou Michal a induzir uma ereção artificial passiva, pela introdução de soro heparinizado nos corpos cavernosos. Durante a ereção artificial, o sistema arterial do pênis é dilatado e alongado o trajeto tortuoso das artérias.

0 uso desta técnica, que Michal chamou de Faloarteriografia, tem algumas vantagens. Primeiro, qualquer deformidade do pênis durante a ereção torna-se imediatamente visível. Segundo, a circunferência do pênis, durante a ereção artificial, pode ser medida e serve como termo de comparação, podendo conhecer-se a percentagem de ereção completa que o doente pode obter.

Posteriormente, Virag usou a papaverina intracavernosa antes da realização da arteriografia seletiva da hipogástrica, que permitia obter uma melhor visualização das artérias pudendas e seus ramos e, portanto, uma melhor interpretação das lesões arteriográficas.

Resultados - A arteriografia pode demonstrar dois tipos de lesões: a primeira, uma doença aorto-iliaca, onde a disfunção erétil está muitas vezes associada com arteriopatia dos membros inferiores, que é, usualmente, demonstrada pela aorto-arteriografia. A lesão mais caracterizada é a oclusão da aorta terminal (Sindrome de Leriche) ou a oclusão da ilíaca comum ou das ilíacas internas. Uma segunda situação que pode haver é a sindrome de roubo, quando há uma oclusão da iliaca comum. 0 membro atingido é alimentado pela iliaca interna contra lateral e seus ramos. As lesões da artéria pudenda interna e seus ramos podem sofrer estenoses, oclusões, displasias ou alterações hemodinâmicas, que são sugeridas par sinais indiretos: injeção compensatória pela artéria cavernosa oposta, cavernograma ao nivel de uma oclusão de uma artéria cavernosa, hipertrofia compensatória contra lateral. 
A análise da arteriografia deve definir o local das lesões (segmento atingido) e qual o lado atingido. As lesões mais distais têm efeito funcional maior, enquanto as lesões proximais só intervêm na ereção quando são oclusivas ou são estenoses hemodinamicamente significativas (bilaterais).

As limitações do método são a complexidade do exame, a dificuldade de interpretação e a impossibilidade de avaliação hemodinâmica quantitativa, que, de resto, é atributo que falta a qualquer exame angiográfico.

0 uso de uma técnica correta com um bom posicionamento do doente, em posições obliquas, para evitar sobreposição de imagens, praticamente evita qualquer tipo de complicação, para aquelas que são inerentes a qualquer exame angiográfico.

0 uso associado da papaverina provocaria o relaxamento dos músculos lisos das colunas intracavernosas, o que arrastaria a uma reação arterial secundária das artérias helicinais, com conseqüente preenchimento dos corpos cavernosos. Atualmente, o uso de fármacos vasoativos, principalmente da prostaglandina E1, é corrente na realização das angiografias seletivas das hipogástricas, no sentido de obter melhores imagens dos ramos terminais das artérias pudendas. A angiografia tem também interesse no controle da cirurgia realizada, sendo as técnicas de Seldinger e ultimamente a angiografia digital, as mais utilizadas.

Complicações- Inerentes a todas as técnicas de punção arterial e às reações alérgicas aos contrastes que certamente podem ser prevenidas com testes de sensibilidade.

\section{Estudo hormonal da disfunção erétil}

0 estudo standard da disfunção erétil compreende a determinação dos niveis séricos de testosterona (total e livre) IH a nrolacting $\mathrm{Fm}$ 
individuos acima de 50 anos, é sempre preferivel determinar a testosterona livre, pois esta representa melhor a função androgênica das células de Leydig, pois devido à involução fisiológica das mesmas, própria do envelhecimento, existe um significativo decréscimo progressivo da secreção androgênica testicular e dos niveis séricos de testosterona circulante total e livre, principalmente para a fração livre devido à elevada produção da proteína plasmática transportadora de hormônios sexuais (SHBG) por incremento dos estrógenos circulantes, no homem idoso.

A presença de um baixo nivel de LH circulante basal exige realizar um teste de estimulação com RH-LH para confirmar ou descartar a existência de um déficit de LH. 0 propósito do perfil hormonal é detectar hipoandrogenismo ou hiperprolactinemia.

Indicações do estudo hormonal - No homem com disfunção erétil não psicogênica, o estudo hormonal deve ser realizado sistematicamente.

Interpretação do estudo hormonal - A existência de um nível sérico baixo de testosterona (total ou livre) revela um déficit androgênico (hipogonadismo). A elevação do LH sérico basal reflete um déficit funcional das células de Leydig (hipogonadismo hipergonadotrófico ou primário). Uma hipo-resposta de LH após estímulo com LH-RH confirma a existência de déficit gonadotrófico (hipogonadismo hipogonadotrófico ou secundário) nos casos de baixo nivel sérico de LH circulante basal. A elevação mantida em 3 determinações da prolactina sérica basal revela uma hiperprolactinemia. Se os niveis de prolactina são inferiores a $100 \mathrm{ng} / \mathrm{ml}$, é provável que não se trate de um prolactinoma; no entanto, se há niveis superiores a $100 \mathrm{ng} / \mathrm{ml}$, estes sugerem um possivel prolactinoma.

A constatação de uma causa endócrina, em uma disfunção erétil, não descarta a coexistência de outros fatores causais, dada à etiologia multifatorial da disfunção erétil. 


\section{Avaliação neurofisiológica}

0 exame clínico neurológico, em geral, não fornece dados de importância, exceto nos casos evidentes de lesão medular, lesões dos hemisférios cerebrais com comprometimento periférico evidente ou lesões motoras periféricas bem caracterizadas. Na história, sintomas neurológicos, associados à presença de sinais evidentes (diminuição dos reflexos, tendinosos profundos, ausência de reatividade do reflexo bulbocavernoso), fazem suspeitar de doença neurológica como causa da impotência.

Geralmente recorre-se aos estudos neurofisiológicos para estudo das vias sensitivas e motoras periféricas e centrais. Clinicamente pode-se avaliar a integridade do arco reflexo medular, pela presença do reflexo cutâneo-anal, porém sem segurança com a possivel relação deste achado com significados neurológicos mais consistentes.

Biotensiometria peniana - Este é o exame inicial para avaliação das vias sensoriais aferentes em pacientes suspeitos de terem lesões neurológicas (diabéticos, alcoólatras e outros). É realizado mediante a aplicação de estímulos vibratórios sobre o pênis, emitidos a partir de instrumentos eletromagnéticos, capazes de regularem a freqüência e amplitude das vibrações emanadas a partir de uma placa colocada sob o pênis. Biotensiometria não é, por si só, diagnóstico; porém, quando alterada, é indicativa da necessidade de uma mais aprofundada pesquisa neurofisiológica.

0 exame consiste na comparação entre a sensibilidade vibratória sobre o pênis e uma área do corpo, geralmente a polpa digital. 0 paciente é argüido sobre se sente a mudança da intensidade da vibração nos dois locais. Em pacientes normais, e possivel distinguir vibrações produzidas com amplitudes inferiores a 10V. Entre 10-20 V situa-se uma zona de valores discutiveis que necessitam de outras avaliações neurológicas, 
do pênis. Acima de 20-30 V são os valores geralmente encontrados em pacientes com alterações neurológicas.

Reflexo bulbo-cavernoso - A partir de medidas da latência do reflexo bulbo-cavernoso, pode-se ter uma idéia da integridade das vias aferentes e eferentes somáticas da área sacral. Usando-se um estímulo elétrico desencadeado a partir da glande (somato-somático), ou da uretra (víscerosomático) e obtendo-se registros da atividade muscular elétrica ao nivel perineal (musculatura bulbo-cavernosa), pode-se obter periodos de latência normais até $38 \mathrm{mseg}$ (variando até $42 \mathrm{mseg}$ para outros autores) para o reflexo somato-somático, e até 60 mseg para o reflexo víscero-somático.

Velocidade de condução do nervo dorsal do pênis - Determinado a partir dos reflexos bulbo-cavernosos, com estímulos localizados em locais distintos do pênis (ao nivel da glande, no meio do corpo do pênis e na base peniana). Uma vez determinada a latência de cada estimulo e conhecendo-se a distância entre dois pontos, onde foram feitos os estímulos elétricos, pode-se calcular a velocidade de condução do nervo dorsal do pênis, via responsável pela transmissão aferente do arco reflexo.

Potenciais evocados gênito-cerebrais - Investiga a integridade das vias córtico medulares. Consiste no registro do potencial evocado ao nível lombar medular e cortical, após estímulo elétrico desencadeado na superfície dorsal do pênis. 0 tempo de latência do potencial evocado cerebral oscila ao redor de 43,4 mseg, ao nivel cerebral, e ao redor de 10 mseg ao nivel lombar.

\section{Referências bibliográficas}

TULLI, R. E., Pinto, A. F. C., VACCARI, R. Impotência- diagnóstico e tratamento. São Paulo, 1991.

MONSENEY, J. M. P., ARRONDO, J. L. A. Práctica Andrológica. Barcelona: Masson-Salvart, 1994. 
ANDRADE SILVA, M.C., SERAPIÃO, J.J., JURBERG, P. (Orgs) Sexologia. Fundamentos para uma visão interdisciplinar. Rio de Janeiro: Universidade Gama Filho, 1997.

CANEllA, P. R. B. Sexologia e Medicina - Aspectos Bio-psico-sociais. Rio de Janeiro. Edição do autor para o Mestrado em Sexologia - UGF e Instituto de Ginecologia - UFRJ, 2003

CARSON, C., KIRBY, R., GOLDESTEIN, I. Textbook of erectile dysfunction. Oxford: Isis Medical Media, 1999.

MOREIRA, A . A disfunção sexual. Porto, 1999.

PINTO, O.E., TULLI R.E., ROMERO A.D., DEGNI M., SCOPETTA L.D. Cavernosografia: Estudo e interpretação de 250 casos. Imagem, v.4, p. 121-126, 1987. 